Sutasoma: Journal of Javanese Literature

\title{
WANDANING RINGGIT WACUCAL DALAM KAJAN FILOLOGIS
}

\section{Candi Asri Dewi $\bowtie$}

Jurusan Bahasa dan Sastra Jawa, Fakultas Bahasa dan Seni, Universitas Negeri Semarang, Indonesia

\begin{tabular}{l}
\hline Info Artikel \\
\hline Sejarah Artikel: \\
\hline Keywords: \\
Filologi, Naskah, Wanda \\
Ringgit. \\
\hline
\end{tabular}

\begin{abstract}
Abstrak
\end{abstract}
Tujuan penelitian ini adalah sajian berupa deskripsi naskah Wandaning Ringgit Wacucal, transliterasi dan suntingan naskah Wandaning Ringgit Wacucal, serta terjemahan teks Wandaning Ringgit Wacucal. Data dan sumber data penelitian ini adalah naskah Wandaning Ringgit Wacucal yang tersimpan di Museum Radya Pustaka Surakarta. Metode yang digunakan adalah metode naskah tunggal. Terjemahan naskah Wandaning Ringgit Wacucal menggunakan terjemahan bebas. Hasil penelitian menunjukkan bahwa naskah Wandaning Ringgit Wacucal merupakan naskah tunggal. Sebelumnya telah dijelaskan naskah Wandaning Ringgit Wacucal merupakan naskah kedua, disebutkan naskah pertama pada katalog Nancy K Florida tersimnpan di Keraton Surakarta. Setelah dilakukan penelusuran naskah yang dimaksudkan tidak ditemukan. Katalog Induk Naskah-naskah Nusantara Jilid 3B Universitas Indonesia juga menyebutkan terdapat naskah dengan keterangan salinan dari dua naskah yang terdapat di Surakarta dengan judul Pratelanipun Wandaning Ringgit Wacucal. Setelah dilakukan penulusuran data dari segi usia yang lebih muda dan kelengkapan yang kurang naskah tersebut tidak digunakan dan tetap menggunakan naskah Wandaning Ringgit Wacucal. Naskah tersebut hanya terdapat di Museum Radya Pustaka Surakarta dengan kode penyimpanan SMP-RP 244, tebal 28 halaman, dituliskan dengan aksara Jawa, menggunakan bahasa Jawa dan ditulis dalam bentuk prosa. Naskah Wandaning Ringgit Wacucal berisi tentang deskripsi bagian-bagian tubuh wayang, mulai dari bentuk wajah, bentuk tubuh, hingga bentuk gelungan. Penelitian ini menghasilkan edisi teks yang sahih menurut kajian filologis. Aparat kritik disertakan dan teks ini diterjemahkan dalam bahasa Indonesia. Peneliti menemukan kendala dalam menyajikan naskah Wandaning Ringgit Wacucal di 
antaranya adalah terdapatnya kata-kata dalam bahasa pewayangan yang sukar untuk diartikan ke bentuk bahasa Indonesia.

\section{Abstract}

The purpose of this study was a presentation in the form of a description of the Wandaning Ringgit Wacucal manuscript, transliteration and edits of the Wandaning Ringgit Wacucal manuscript, as well as the translation of the Wandaning Ringgit Wacucal text. Data and data sources of this study are Wandaning Ringgit Wacucal manuscripts which are stored in the Radya Library of Surakarta Museum. The method used is a single script method. Translation of the Wandaning Ringgit Wacucal manuscript uses free translation. The results showed that the Wandaning Ringgit Wacucal manuscript was a single text. Previously explained the Wandaning Ringgit Wacucal text was the second manuscript, mentioned the first manuscript in the Nancy K Florida catalog hidden in the Surakarta Palace. After searching the manuscript intended is not found. The Master Catalog of Archipelago Manuscripts Volume $3 B$ Universitas Indonesia also mentions that there is a text with a description of copies of two manuscripts in Surakarta with the title Pratelanipun Wandaning Wacucal Ringgit. After searching the data in terms of younger age and lack of completeness, the manuscript was not used and continued to use the Wandaning Ringgit Wacucal text. The manuscript is only available at the Radya Museum Surakarta Library with a SMP-RP 244 storage code, 28 pages thick, written in Javanese script, using Javanese and written in prose. The Wacucal Ringgit Manuscript contains a description of the body parts of the puppet, starting from the face shape, body shape, to the shape of the coil. This study produced a valid edition of the text according to philological studies. Critical apparatus is included and this text is translated in Indonesian. The researcher found an obstacle in presenting the Wandanucan Ringgit manuscript, including the presence of words in puppet language which are difficult to interpret into Indonesian.

CUniversitas Negeri Semarang

\footnotetext{
Alamat korespondensi:

Gedung B8 Lantai 1 FBS Unnes

Kampus Sekaran, Gunungpati, Semarang, 50229

E-mail: widodo.unnes82@gmail.com
}

ISSN 2252-6463 


\section{PENDAHULUAN}

Indonesia merupakan kesatuan yang memiliki berbagai macam adat istiadat dan kebudayaan. Adat istiadat tersebut tersebar di setiap daerah asal budaya dan dipercayai oleh masyarakat penganutnya. Hasil kebudayaan tersebut dua macam yaitu, kebudayaan yang tertulis dan kebudayaan lisan. Sebagai contoh kebudayaan lisan adalah cerita rakyat yang dari generasi ke generasi diceritakan secara turun temurun. Kebudayaan tulis meliputi naskah-naskah kuno yang berisi hasil kebudayaan dan buah pikir.

Naskah adalah semua dokumen tertulis yang ditulis tangan. Menurut Library and Information, semua naskah adalah semua barang tulisan tangan yang ada pada koleksi perpustakaan atau arsip. Teks adalah data yang terdiri dari karakter-karakter yang menyatakan kata-kata atau lambang-lambang untuk berkomunikasi oleh manusia dalam bentuk tulisan. Terdapat naskah Jawa yang tersebar di beberapa Perpustakaan Wilayah dan Daerah maupun di Museum Daerah serta di Keraton Yogyakarta maupun Surakarta. Museum Sonobudoyo Yogyakarta, Museum Radya Pustaka Surakarta, Museum Ranggawarsito Semarang, Perpustakaan Wilayah Semarang, dan Keraton Yogyakarta merupakan tempat-tempat yang menyimpan koleksi naskah Jawa. Naskah Jawa memakai lontar (ron tal 'daun tal' atau 'daun siwalan'), dan dluwang, yaitu kertas Jawa dari kulit kayu; naskah Bali dan Lombok memakai lontar, naskah Batak memakai kulit kayu, bambu, rotan.

Naskah yang menjadi data penelitian ini adalah naskah Wandaning Ringgit Wacucal.
Naskah ini menggunakan tulisan dengan aksara Jawa, sehingga untuk penelitiannya menggunakan beberapa kritik teks, di antaranya adalah : (1) pembacaan teks, (2) deskripsi naskah, (3) transliterasi (penggantian jenis aksara), (4) rekonstruksi teks, (5) penyuntingan teks, dan (6) penerjemahan teks.

Dilakukannya penelitian menggunakan naskah Wandaning Ringgit Wacucal ini adalah pertama naskah tersebut belum ada yang meneliti atau digunakan sebagai subjek penelitian filologi sejauh peneliti ketahui. Kedua, naskah tersimpan di Museum Radya Pustaka dengan nomor penyimpanan SMP-RP 244 dengan tebal 25 halaman dan sangat terlihat apabila penulisan sudah sangat lengkap. Dimulai pada awal naskah terdapat kalimat 'katur angger raden ngabei karya rurjita pratelan' yang artinya adalah 'dipersembahkan untuk Putra Raden Ngabei Karya Rurjita Pratelan' dan diakhiri dengan adanya kalimat 'ingkang nyerati kawula pun. ingkang nginggahaken' yang artinya 'saya yang menulis, yang menyimpan'.

Ketiga, naskah ditulis menggunakan tulisan tangan dan menggunakan aksara Jawa yang masih terdapat masyarakat yang belum memahami isi di dalam naskah tersebut. Keempat, kondisi naskah masih sangat baik dan mudah untuk dibaca. Kelima, umur naskah yang sudah sangat tua yang dapat diketahui dari tulisan di dalam naskah. Naskah Wandaning Ringgit Wacucal di dalamnya terdapat tulisan Ugerran kaping : 24 : agustus, 1913, jadi, dapat di perkirakan umur naskah tersebut adalah 101 tahun sehingga harus segera dilakukan transletrasi agar naskah tetap terjaga dan lestari. Naskah 


\section{Candi Asri Dewi, Widodo, Hardyanto, Yusro Edy Nugroho / SUTASOMA}

Wandaning Ringgit Wacucal termasuk golongan naskah dalam bentuk prosa yang berisi tentang seluk beluk wayang atau identitas wayang.

Naskah ini dapat diteliti melalui beberapa bidang ilmu, di antaranya adalah bidang ilmu linguistik, ilmu sastra, serta ilmu filologi. Adanya penggambaran spesifikasi mengenai anggota tubuh wayang akan memberikan informasi dan tambahan pengetahuan masyarakat yang masih awam, serta juga bisa dijadikan bahan ajar untuk siswa sebagai pengenalan wayang sebagai budaya Indonesia.

Adapun rumusan masalah penelitian tersebut yaitu bagaimana menyajikan teks naskah $W R W$ secara sahih menurut kajian filologi?. penelitian ini juga bertujuan menyajikan teks naskah $W R W$ secara sahih menurut kajian filologi yang bersih dari kesalahan.

\section{METODE PENELITIAN}

Data yang diteliti adalah teks naskah Wandaning Ringgit Wacucal. Judul naskah Wandaning Ringgit Wacucal terdapat pada halaman depan naskah yang juga tertulis pada katalog Nancy Florida di Museum Radya Pustaka Surakarta. Naskah Wandaning Ringgit Wacucal berisi 28 halaman dengan nomor penyimpanan pada museum Radya Pustaka Surakarta SMP-RP 244. Pada katalog Nancy Florida naskah tertulis halaman sebanyak i+31 yang ditotalkan menjadi 32 halaman. Akan tetapi pada data hasil scanning maupun naskah yang ada hanyalah 28 halaman. Naskah Wandaning Ringgit Wacucal merupakan naskah kedua, yang pada katalog telah dijelaskan bahwa naskah pertama tersimpan di Keraton
Surakarta. Setelah dilakukan penelusuran data, naskah yang dituliskan pertama sudah tidak ada. , namun tidak ditemukan naskah yang sama sebagaimana naskah Wandaning Ringgit Wacucal yang menjadi sumber penelitian. Katalog Induk Naskah-Naskah Nusantara Jilid 3B Fakultas Sastra Universitas Indonesia juga menyebutkan terdapat naskah dengan keterangan salinan dari dua naskah yang terdapat di Surakarta dengan judul Pratelanipun Wandaning Ringgit Wacucal. Setelah dilakukan penelusuran data, naskah tersebut tidak digunakan sebagai tambahan data karena dari segi usia yang lebih muda dan kelengkapan kurang dibanding dengan naskah Wandaning Ringgit Wacucal.

Metode yang digunakan dalam penelitian ini adalah metode translitersi atau alih aksara. Transletrasi adalah alih aksara atau penggantian jenis aksara dengan aksara dari abjad lain. Dapat juga disebutkan dengan kata lain, transliterasi adalah penggantian jenis tulisan, huruf demi huruf, dari abjad yang satu abjad ke abjad lain.

\section{Teks Wandaning Ringgit Wacucal} merupakan teks dengan tulisan aksara Jawa dan bahasa Jawa, sehingga harus dialihaksarakan menjadi huruf latin. Adanya transliterasi ini, bertujuan agar masyarakat atau pembaca yang masih awam dalam pembacaan aksara Jawa dapat dengan mudah untuk memahami isi di dalam naskah. Teks transliterasi akan disajikan dengan memperhatikan ejaan yang bersangkutan. Ciri ragam bahasa lama, dipertahankan bentuk aslinya, tidak disesuaikan penulisannya dengan penulisan menurut EYD 
supaya data mengenai bahasa lama dalam naskah tidak hilang (Basuki 2004:55).

\section{WANDANING RINGGIT WACUCAL}

\begin{tabular}{|c|c|c|c|}
\hline \multicolumn{4}{|c|}{ DESKRIPSI NASKAH } \\
\hline 1 & Judul & : & $\begin{array}{l}\text { Wandaning Ringgit } \\
\text { Wacucal. }\end{array}$ \\
\hline 2 & $\begin{array}{l}\text { Nama } \\
\text { Pengar } \\
\text { ang }\end{array}$ & : & R.Ng. Karyarujita. \\
\hline 3 & $\begin{array}{l}\text { Tempat } \\
\text { penyim } \\
\text { panan }\end{array}$ & : & $\begin{array}{l}\text { Museum Radya Pustaka } \\
\text { Surakarta. }\end{array}$ \\
\hline 4 & Huruf & : & Aksara Jawa. \\
\hline 5 & Bentuk & : & Prosa. \\
\hline 6 & $\begin{array}{l}\text { Kode } \\
\text { penyim } \\
\text { panan }\end{array}$ & : & SMP-RP 244. \\
\hline 7 & $\begin{array}{l}\text { Tahun } \\
\text { penulis } \\
\text { an }\end{array}$ & : & 1912. \\
\hline 8 & $\begin{array}{l}\text { Lokasi } \\
\text { penulis } \\
\text { an }\end{array}$ & : & $\begin{array}{ll}\text { Lingkungan } & \text { Keraton } \\
\text { Surakarta. } & \end{array}$ \\
\hline 9 & $\begin{array}{l}\text { Ukuran } \\
\text { naskah }\end{array}$ & : & $16 \times 20,5 \mathrm{~cm}$. \\
\hline 10 & $\begin{array}{l}\text { Jenis } \\
\text { kertas }\end{array}$ & : & $\begin{array}{l}\text { Kertas bergaris dengan } \\
\text { bahan HVS kuna. }\end{array}$ \\
\hline 11 & $\begin{array}{l}\text { Jumlah } \\
\text { halama } \\
\text { n }\end{array}$ & : & 28 halaman. \\
\hline 12 & $\begin{array}{l}\text { Jumlah } \\
\text { baris }\end{array}$ & & $\begin{array}{ll}\text { Halaman pertama } & 22 \\
\text { baris, halaman kedua } & 16 \\
\text { baris, halaman ketiga } & 23 \\
\text { baris, halaman } & \\
\text { keempat } 8 \text { baris, halaman }\end{array}$ \\
\hline
\end{tabular}

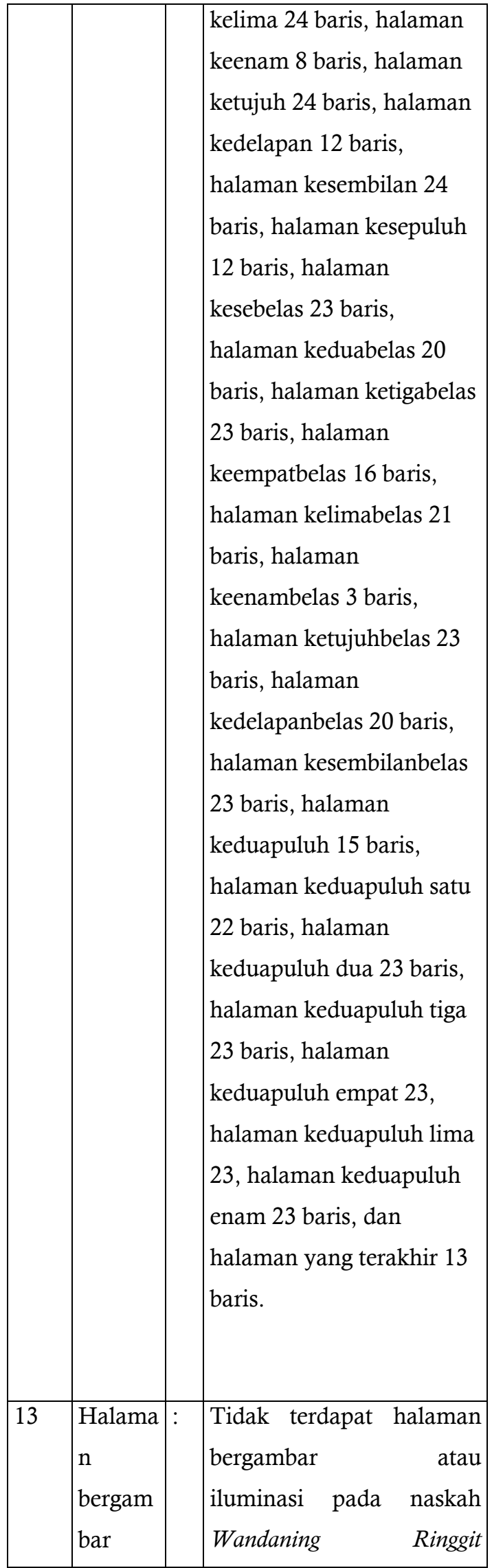


Candi Asri Dewi, Widodo, Hardyanto, Yusro Edy Nugroho / SUTASOMA

\begin{tabular}{|c|c|c|}
\hline & & Wacucal. \\
\hline 14 & $\begin{array}{l}\text { Keadaa } \\
\text { n } \\
\text { naskah }\end{array}$ & $\begin{array}{l}\text { Naskah utuh tanpa ada } \\
\text { yang sobek. Warna kertas } \\
\text { coklat kekuningan, } \\
\text { dengan warna tinta hitam. } \\
\text { Terdapat satu paragraf } \\
\text { yang ditulis dengan tinta } \\
\text { merah. }\end{array}$ \\
\hline 15 & $\begin{array}{l}\text { Pemilik } \\
\text { naskah }\end{array}$ & $\begin{array}{l}\text { Museum Radya Pustaka } \\
\text { Surakarta. }\end{array}$ \\
\hline 16 & $\begin{array}{l}\text { Catatan } \\
\text { lain } \\
\text { naskah }\end{array}$ & 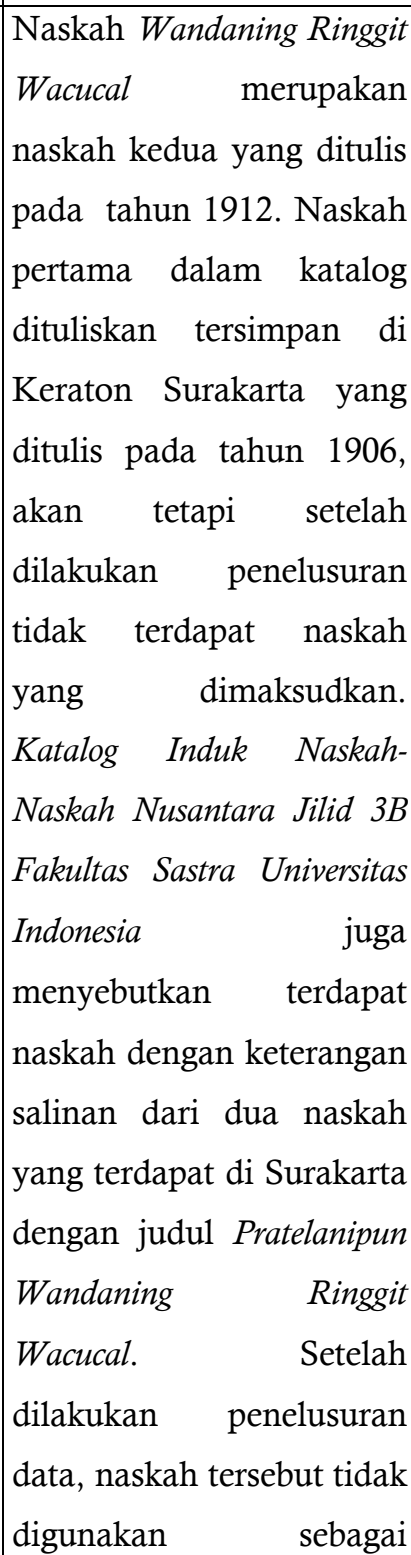 \\
\hline
\end{tabular}

\begin{tabular}{|c|c|c|}
\hline & & $\begin{array}{l}\text { tambahan data karena dari } \\
\text { segi usia yang lebih muda } \\
\text { dan kelengkapan kurang } \\
\text { dibanding dengan naskah } \\
\text { Wandaning Ringgit } \\
\text { Wacucal. Sehingga dalam } \\
\text { penelitian, peneliti tetap } \\
\text { menggunakan naskah } \\
\text { kedua yang tersimpan di } \\
\text { Museum Radya Pustaka } \\
\text { Surakarta. }\end{array}$ \\
\hline 17 & $\begin{array}{l}\text { Isi } \\
\text { ringkas } \\
\text { naskah }\end{array}$ & 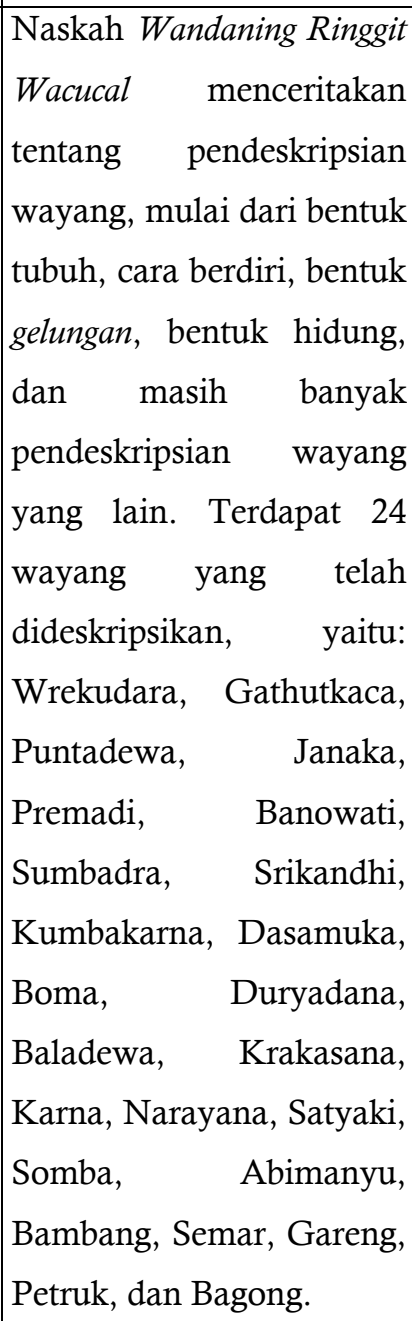 \\
\hline
\end{tabular}




\section{Suntingan Teks Wandaning Ringgit Wacucal}

Wandaning Ringgit Wacucal. Katur Anggèr

Radèn Ngabéi Karya Rurjita.

:Pratélan:

1. Bima, lina, tumungkul badan lema,

2. " , mimis, longok, singset,

3. " , jagu, lindhu kalongok sawatawis.

4. “ , gurnat, longok kados bima mimis, badan ageng.

1. Repruna, kinanthi, tumungkul sanget, sumping boten katatah.

2. malatsih, kinanthi dipunlongokaken.

3. mangu, malatsih radi manganglu, gelungipun beda.

4. kanyat, sahingga mangu, jongga boten manganglu.

5. jimat, longok gelung radi ngadeg.

Katerangaken, ingkang makaten punika, sanèssanèsipun malih kula sumangga anggèr, kula manah anggèr sampun saged, bilih kula ingkang garap rekaos, amargi sampun se[2] puh. Kajawi punika, kula cariyos, kala rumiyin kula asring reraséyan kaliyan dhalang, utawi juru natah wayang, "Bala Dewa gègèr, gadhahanipun dhalang nganu, kaliyan dhalang nganu, kula kok remen dhalang nganu, wangsulanipun kaleresan anggènipun nyorèk, tuwin ambedhahi, utawi boten kaleresan. "Bima, Kresna, Arjuna, makaten ugi. Kejawi punika manawi amarengaken, kula nyuwun cathetan wandanipun ringgit, tedhakan saking keraton, ingkang mawi katrangan ingkang yasa, kados ingkang kaparengaken Mas Demang Redisuta.

Senèn kaping, 11, Rabingulakir, 6 Ruwah: 1836 Punwa, (w.g.) Prajatani [3] 5/5 36 a. Lindhu, tumungkul, gelung sedheng, pudhak andhap ngajeng, badan lema, adegipun angrong

b. Mimis, longok sawatawis, gelung ragi alit, pundhak pajeg, badan singset, adegipun pajeg.

c. Gurnat, longok gelung sedheng, pundhak pajeg, badan ageng adegipun pajeg.

d. (mimis badan ageng).

e. Jagur, longok sawatawis, gelung sedheng pundhak andhap ngajeng, badan ageng, adegipun angrong.

f. Lintang, longok, gelung sedheng, pundhak pajeg, badan wiwing, adegipun pajeg.

2. Gathutkaca,

a. Guntur, tumungkul, gelung sedheng, pundhak andhap ngajeng, badan ageng, adegipun angrong.

b. Gelap, longok sawatawis, pundhak pajeg, badan singset, adegipun pajeg.

c. Thathit, radi tumungkul, jongga manganglu, pundhak andhap ngajeng, badan singset, ade[4] gipun pajeg.

d. Kilat, longok, pundhak pajeg, badan singset, adegipun pajeg. (w.g.) Karya Rujita kasebut ing nginggil puni ka kula sampun anyondhongi. (w.g.) Prajatani

\section{Terjemahan Teks Wandaning Ringgit Wacucal.}

Dipersembahkan untuk Putra Raden Ngabei Karya Rurjita Keterangan.

1. Bima, bentuk lina, menunduk berbadan gemuk.

2. Bima, bentuk mimis, melongok, badan langsing.

3. Bima, bentuk jagu, bentuk lindhu, agak melongok.

1. Wrekudara 
4. Bima, bentuk gurnat, melongok seperti bima bentuk mimis, berbadan besar.

5. Repruna, bentuk kinanthi, sangat menunduk, tidak banyak terdapat sumping.

6. Repruna, bentuk malatsih, bentuk kinanthi kepala yang melongok.

7. Repruna, bentuk mangu, malatsih agak melongok, gelung rambut berbeda.

8. Repruna, bentuk kanyat, agak mangu, leher tidak melengkung.

9. Repruna, bentuk jimat, melongok, gelung agak ke atas.

Sudah dijelaskan sebelumnya (penjelasan di atas Bima dan Repruna), yang lain saya persilahkan ananda, saya pikir ananda sudah mengerti, saya yang kesulitan mengerjakan karena sudah tua[2]. Selain itu saya bercerita, dulu saya sering berbincangbincang dengan dalang atau juru pembuat wayang. "Bala dewa bentuk geger, milik dalang anu, dengan dalang anu, saya suka dengan seorang dalang anu, jawabnya kebetulan saja saat menggambarkan dan membedah atau tidak berkenan." "Begitu pula dengan Bima, Kresna, Arjuna."

Selain itu jika diizinkan, saya minta catatan bentuk-bentuk wayang salinan dari keraton, dengan keterangan pembuatnya, seperti yang diizinkan oleh Mas Demang Redisuta. Senin ke, 11, Rabingulakir, 6 Ruwah : 1836 Punwa, (ttd) praratani [3]

1. Wrekudara

1. Bentuk lindhu, menunduk, gelung sedang, bahu membungkuk, badan gemuk, berdirinya tegap.
2. Bentuk mimis, sedikit melongok, gelung agak kecil, bahu tegap, badan lencir, berdirinya tegap.

3. Bentuk gurnat, melongok, gelung sedang, bahu tegap, badan besar, berdirinya tegap. (bentuk mimis badan besar)

4. Bentuk jagur, sedikit longok, gelung sedang, bahu membungkuk, berdirinya angrong.

5. Bentuk lintang, melongok, gelung sedang, bahu sedang, badan kecil, berdirinya tegap.

2. Gathutkaca,

1. Bentuk guntur, menunduk, gelung sedang, bahu membungkuk, badan besar, berdirinya tegap.

2. Bentuk gelap, sedikit melongok, bahu tegap, badan langsing, berdirinya tegap.

3. Bentuk thathit, agak menunduk, leher melongok, bahu membungkuk, badan langsing, berdiri [4] nya tegap.

4. Bentuk kilat, melongok, bahu tegap, badan langsing, berdirinya tegap. (ttd) karya rujita yang telah disebutkan di atas sudah saya setujui. (ttd) Prajatani

\section{SIMPULAN}

Naskah Wandaning Ringgit Wacucal merupakan naskah tunggal yang tersimpan di Museum Radya Pustaka Surakarta. Setelah dilakukan penelusuran, terdapat naskah yang serupa dengan naskah Wandaning Ringgit Wacucal terdapat di Perpustakaan Universitas Indonesia yang berjudul Pratelaning Wandanipun Ringgit Wacucal. Naskah tersebut 
dijelaskan dalam Katalog Induk Naskah-naskah Nusantara Jilid $3 B$ Universitas Indonesia merupakan salinan dari dua naskah yang ditemukan di Surakarta. Apabila dilihat dari segi kelengkapan dan usia, naskah tersebut lebih muda dibanding naskah yang tersimpan dalam Museum Radya Pustaka yaitu dari tahun 1929. Sehingga peneliti menggunakan naskah yang berada di Museum Radya Pustaka sebagai data penelitian. Berdasarkan studi katalog berupa manual atau online, naskah Wandaning Ringgit Wacucal belum pernah diteliti dalam kajian filologis.

Bentuk naskah Wandaning Ringgit Wacucal adalah prosa yang terdiri dari 28 halaman. Naskah Wandaning Ringgit Wacucal mendefinisikan wanda atau bagian tubuh atau bentuk tubuh, serta bentuk wajah dalam tokoh wayang kulit. Teks Wandaning Ringgit Wacucal telah disunting serta diterjemahkan dalam bentuk bahasa Indonesia yang telah dipaparkan dalam bab IV.

\section{DAFTAR PUSTAKA}

Balai Bahasa Yogyakarta. 2011. Pedoman Umum Ejaan Bahasa Jawa Huruf Latin yang Disempurnakan. Jakarta: Kementrian Pendidikan Nasional.

Baried Baroroh, Sulastin Sutrisno, Siti Chamamah, Soeratno, Samu, Kun Zachrun Istanti. 1983. Pengantar Teori Filologi. Yogyakarta: Badan Penelitian dan Publikasi UGM.

Basuki, Anhar. 2004. Pengantar Filologi. Semarang : Dana Proyek SP4 Fakultas Sastra Universitas Diponegoro.
Behrend, T.E. 1997. Katalog Induk Naskahnaskah Nusantara Jilid 3-A, Fakultas Sastra Universitas Indonesia. Jakarta: Obor Indonesia.

1997. Katalog Induk Naskahnaskah Nusantara Jilid 3-B, Fakultas Sastra Universitas Indonesia. Jakarta: Obor Indonesia.

Boas, NF, James Ruddy, Ivo Meisner, John Rhodeham. 1990. The Manuscript Society Criteria for Describing Manuscripts and Documents.

Darusuprapta, dkk. 1995. Pedoman Penulisan Aksara Jawa. Yogyakarta: Yayasan Pustaka Nusatama.

Dipodjojo, Asdi S. 1996. Memperkirakan Titimangsa Suatu Naskah. Lukman Ofset Yogyakarta.

Djamaris, Edwar. 1991. Metode Penelitian Filologi. Jakarta: Pusat Pembinaan dan Pengembangan Bahasa Depdikbud.

Ghani, DA, Sidin Bin Ahmad Ishak. 2012. Relationship Between The Art of Wayang Kulit and Disney's Twelve Principles of Animation. Lumen Publishing House.

Girardet, Nikolaus. 1983. Descriptive Catalogue of the Javanese Manuscriots and Printed Books in the Main Libraries of Surakarta and Yogyakarta. Franz Steiner Verlag GMBH-Wiesbaden: Universitat Heidelberg. 
Hartono, Rudi. 2009. Teori Penerjemahan : A Handbook for Translators. Semarang: Cipta Prima Nusantara.

Hulle, Dir Van. 2009. "The dynamics of Incompletion: "Multlingual manuscript Genetics and Digital Philology. Journal of Phililogy. Akade'miai Kiado, Budapest, Hungary.

Kozok, Uli. 1999. Warisan Leluhur : Sastra Lama dan Aksara Batak. Jakarta: Kepustakaan Populer Gramedia (KPG).

Mulyadi, S.W.R. 1991. Naskah dan Kita. Depok: Fakultas Sastra Universitas Indonesia.

Nederhof, MJ. 2009. Automatic Creation of Interlinear Text for Philological Purposes. School of Computer Science, University of St Andrews, North Haugh, St Andrews, Fife, KY16 9SX, Scotland.

Patil. P.G. 2010. Jonardon Ganeri's Philosophy in Classical India : "History, Philology, and the Philosophical study of Sanskrit Texts." Journal of Phililogy. Harvard University, Cambrigde. USA.

Perpustakaan Nasional Republik Indonesia. 2013. Katalog Online (OPAC). http://opac.pnri.go.id.

Reynold. dan Wilson. 1991. Scribes \& Scholars. Terjemahan Drs. Bani Sudardi. Surakarta: Universitas Sebelas Maret Surakarta.
Robson, SO. 1994. Prinsip-prinsip Filologi Indonesia. Terjemahan Kencanawati Gunawan. Jakarta: Rul.

Zoetmulder, PJ. 1974. Kalangwan : A Survey of Old Javanese Literature. Koninklijk Instituut voor Taal-, Land-en Volkenkunde. Translation Serirs. 16. The Hague: Martinus Nijhoff. 